ПСИХОЯОГИЯ

УДК: 159.99

\title{
Инициация в специфическом трудовом колдективе, на примере автоматизированных диагностических комплексов ОАО «РЖД»
}

\author{
Максим С. Казаков \\ Донской государственный технический университет, г. Ростов-на-Дону, \\ Российская Федерация \\ E-mail: kazakovm82@mail.ru \\ ORCID ID: https://orcid.org/ 0000-0002-4232-9686
}

\begin{abstract}
Аннотация
В кажАой организации возникают определенные культурные, этические, нравственные, правовые, ритуальные нормы и правила. Наиболее яркими инструментами, в качестве управления организациями, выступают обряды и ритуалы. Аанная статья посвящена применению ритуалов и обрядов в специфрических трудовых комлективах. Основной упор статьи - рассмотрение обряда - инициации. Во ввеАении раскрывается актуальность темы, которая определяется высоким социальным запросом на создание обряловых и ритуальных институтов. Аано определение ритуала и обряла. Рассматривается наиболее востребованный обрял в современном обществе - инициация. В обществе сложилась опреАеленная потребность в инициациях, называемая некоторыми авторами «инициационным голоАом». Аано определение специфичности трудового комлектива, поА которым в рамках Аанной статьи понимается работа социальной группы в условиях социальной изоляции. В Теоретическом обосновании рассматриваются работы, как зарубежных антропологов, этнографров, религиоведов, так и современных фри^ософров и психологов. Так как специфричность трудового кол^ектива в нашем рассмотрении заключается в его изоляции, возникает проблема «входа» в сакральный колмектив. КажАый новичок - стажер, проходит через три сталии. Вначале «отАеляется» из привычно социальной среды, далее проходит периол обучения, во время которого принимает все нормы и правила социальной группы. Аалее происходит стадия «вкАючения», гАе новичок приобретает статус полноценного участника колАектива. В ОбсужАении результатов автор перехолит к Аиалогу с работниками - специалистами ААК (вагонов-путеизмерителей). К обсужАению важности ритуалов, обрядов и особенно инициаций работники отнеслись положительно. В качестве примеров и инструментов инициации, опрошенными специалистами ААK бы^ преАложен целый комплекс технологий и прави^. Оказалось также, что многие из этих специалистов уже применяли обряды и ритуалы в коллективах ААК (вагонах-путеизмерителях) и они были придуманы не сознательно, а стихийно - колмективным бессознательным.
\end{abstract}




\title{
КАючевые слова:
}

инициация, обрял, ритуал, посвящение, мифр, социальная изоляция, трудовой колмектив, архаичность, тралиционное общество, вагон - путеизмеритель

\section{Для цитирования}

Казаков М. С. Инициация в специфическом трудовом коллективе, на примере автоматизированных диагностических комплексов ОАО «РЖД» // Инновационная наука: психология, педагогика, дефектология. 2021. Т. 4, № 2. C. 6-17. doi: https:// doi.org/10.23947/2658-7165-2021-4-2-6-17

\section{Initiation in a specific work collective, exemplified by automated diagnostic systems of Russian Railways}

\author{
Maxim S. Kazakov \\ Don State Technical University, Rostov-on-Don, Russian Federation \\ E-mail: kazakovm82@mail.ru \\ ORCID ID: https://orcid.org/ 0000-0002-4232-9686
}

\begin{abstract}
In each organization, certain cultural, ethical, moral, legal, ritual norms and rules arise. The most prominent examples of tools for managing organizations are rituals and rituals. This article is devoted to the application of rituals and ceremonies in specific work collectives. The focus of the article is on the examination of the initiation rite. The Introduction reveals the relevance of the topic. It is determined by a high social demand for the creation of ritual and ritual institutions. The definition of ritual and ceremony is given. The most demanded rite in modern society - initiation - is considered. A certain need for initiation has developed in society, which some authors call "initiation hunger." The definition of the specificity of the labor collective is given. Within the framework of this article, it refers to the work of a social group in conditions of social isolation. The Theoretical Substantiation examines the works of both foreign anthropologists, ethnographers, religious scholars, and contemporary philosophers and psychologists. Since the specificity of the labor collective lies in its isolation, the problem of "entering" the sacred collective arises. Every novice trainee goes through three stages. First, he "separates" from his usual social environment, then goes through a period of study, during which he accepts the norms and rules of the social group. Then comes the stage of "inclusion", where the newcomer acquires the status of a full-fledged member of the team. In the Discussion of the results, the author proceeds with a dialogue with employees - specialists of ADS (track measuring cars). The workers reacted positively to the discussion of the importance of rituals, ceremonies, and especially initiation. As examples and tools of initiation, the interviewed ADS specialists suggested a whole range of technologies and rules. It turned out that many of these specialists had already
\end{abstract}


ПСИХОЛОГИЯ

used ceremonies and rituals in the collective of ADS (track measuring cars) and they were invented not consciously, but spontaneously - by the collective unconscious.

\section{Keywords}

initiation, ritual, rite, dedication, myth, social isolation, labor collective, archaism, traditional society, track measuring car

\section{For citation}

Kazakov, M. S. (2021). Initiation in a specific work collective, exemplified by automated diagnostic systems of Russian Railways. Innovative Science: psychology, pedagogy, defectology, 4(2), 6-17. doi: https://doi.org/10.23947/2658-7165-2021-4-2-6-17

\section{Введение}

В современном постиндустриальном обществе сформировалась тенденция ухода от традиционных (архаичных) обществ. Данный уход обусловлен смещением ценностей общества в сторону иичности и как следствие разрыв некой традиционной нормы. Разумеется, культурный уход распространился и на профессиональные (трудовые) коллективы. Современные общества и мадые социадьные группы имеют достаточно высокое развитие культуры, где все движется от простого к сложному. В таких восходящих прогрессивных обществах и коллективах социальные отношения и культура автоматически отсекают нормы, культуру и ценности, существовавшие в традиционных (архаичных, или примитивных) обществах. Изменение касается обрядов и ритуалов, которые попросту исчезли, или сильно видоизменились. Многие авторы считают, что ритуалы и обряды просто обязаны быть и в современных коляективах. «Ритуалы позволяют, с одной стороны, отделить священное от профанного, с другой - провести между ними связь и вновь вызвать состояние коляективного возбуждения. В большом коллективе во время ритуала наблюдается деиндивидуализация и повышенная внушаемость личности» (Кузьменков, 2018, с. 153). Ритуал является неким элементом корпоративной культуры (Петровская, Магадова, 2015). Многие обряды и ритуалы стали неофициальным объединяющим фактором в управлении организациями, их значение одновременно очень высоко и недооценено (Архангельская, 2010).

А. С. Архангельская дает определение ритуала. «Ритуал-стереотипная последовательность действий, охватывающая жесты, слова и объекты, исполняемые на специально подготовленном месте и предназначаемые для воздействия на сверхъестественные силы или существа в интересах и целях исполнителей» (Архангельская, 2010, с. 145-146). В рамках данной статьи будем придерживаться этого определения. Определение значения обряда, в рамках 
данной статьи, следующее. Обряд - совокупность ритуалов, выподняемых для предания сакральности, как живому субъекту, так и материальному предмету. Будем придерживаться данных определений.

С одной стороны, ритуалы и обряды направляют вектор развития социальной группы в сторону традиционности и архаичности. С другой стороны, сложности обитания социальной группы, большая зависимость от внешних условия способствуют созданию института обрядов и ритуалов. Это свидетельствует о возможности перехода социальной группы к архаичности, т. е. некий регресс коллектива. «Регресс- переход от высшего к низшему. Регресс включает в себя и моменты застоя, возвращение к отжившим структурам и формам» (Столяренко, Самыгин, Ганиева, 2007, с. 106).

Таким образом, сложные условия бытия социальной группы, а в нашем случае специфического трудового коллектива, образуют подобие архаичного колдектива с институтом обрядов и ритуалов. Э. Дюркгейм достаточно обширно рассмотрел данные архаические общества в своем большом труде. «Неразвитая индивидуальность, небольшие размеры группы, однородность внешних условий все это способствует сведению раздичий и вариативности к минимуму. Группа на регулярной основе создает интеллектуальное и нравственное единообразие, которое в более развитых обществах мы обнаруживаем лишь в редких случаях. Практика стереотипна: в одинаковых обстоятельствах все делают одно и то же, и эта согласованность в поведении дишь отражает согласованность в мышлении» (Дюркгейм, 2018, с. 34).

Под специфическими трудовыми колдективами, которые тяготеют к созданию обрядов и ритуалов, понимаются малые социальные группы, работающие в условиях социальной изоляции.

Социальная изоляция малой группы - это изоляция коллектива (малой социальной группы) в обособленных от остального общества местах временного или постоянного пребывания. В изодированной группе человек вынужденно общается с одними и теми же людьми в процессе работы и отдыха, при этом его отдых резко ограничен. В настоящее время таких колдективов множество. В раздичной степени изоляции подвергаются следующие категории дюдей: космонавты, специадисты профессий, работающие вахтовым методом (полярники, моряки, нефтяники), сюда можно отнести и закдюченных. При этом необходимо взять в расчет дополнительные факторы каждой специфической трудовой социальной группы, а именно: ненормированный рабочий день, работа в ночное время, работа в слишком жарком или хододным помещении, монотонность работы, бортовая качка корабля (судна) для моряков, невесомость для космонавтов и т. д. Все эти социальные и трудовые факторы действуют на психику человека комплексно, обостряя отношения в коллективе и усиливая раздражение и конфликтность. 
ПСИХОЛОГИЯ

К специфическим трудовым коллективам относим и автоматизированные диагностические комплексы ОАО «РЖД» (далее АДК), которым и посвящена данная статья. АДК представдяют собой подвижные единицы, созданные на базе пассажирских вагонов с установленным на них специальным измерительным оборудованием. В некотором смысле это специализированный вагон, который постоянно движется и совмещает функции производственного помещения и жилого дома. Коллектив этих специализированных вагонов (АДК) насчитывает 3-7 человек. Все коллективы АДК работают в условиях социальной изоляции третьей степени.

Данные условия труда и отдыха вышеперечисленных трудовых коллективов, способствуют созданию в коллективах подобие архаичного общества с суровыми институтами и конечно со своими обрядами и ритуалами. Чем тяжелее работа, тем больше обрядов и ритуалов. Эти обряды являются целым институтом, который структурирует всю социальную группу. «Обряды - способы действия, которые возникают тодько в собравшихся вместе группах и предназначены для возбуждения, поддержания или воссоздания определенных ментальных состояний этих групп» (Дюркгейм, 2018, с. 40).

Теперь перейдем к одному из значимых обрядов, это инициация. Инициацией, как социальным фактором занималось множество исследователей, наиболее известный из них - Мирча Элиаде. Именно его определения инициации будем придерживаться. «Под инициацией понимают совокупность обрядов и устных наставлений, цель которых - радикальное изменение религиозного и социадьного статуса посвящаемого» (Элиаде, 1999, с. 12).

Многие специадисты считают, что инициация, в первую очередь, это обряды посвящения мальчиков в архаичных (примитивных) обществах. Данные обряды инициации подробно описаны в знаменитой «Золотой ветви» Д. Д. Фрэзер (Фрэзер, 1983). В современном обществе, как считает Е. А. Аисина, имеется кризис инициационной идентификации, который связывают с отсутствием института мужской инициации (Дисина, 2017). «В современном обществе не существует регулярного механизма инициации: его роль не выполняют полностью ни система образования, ни молодежные субкультуры» (Дисина, 2017, с. 23). И. В. Випулис вводит понятие «инициационный годод», вот как он об этом пишет: «С упразднением общественно-государственных институтов «посвящения» подрастающее поколение потеряло эффективный инструмент регуляции социально-психологического созревания личности» (Випулис, 2019, с. 33). Именно поэтому возникает потребность в инициации молодых людей, которые приходят работать в специфические трудовые колиективы.

Другие авторы рассматривают инициацию, не только как обряд взросления. «В условиях доиндустриальных социальных структур могут иметь место, как обряды перехода, так и обряды инициации. Обряды перехода позводяют 
индивиду пройти весь цикл обрядов жизненного круга (вкдючая возрастные, социальные и т. д.), последовательно идентифицируя себя с нормами, традициями и ролевыми установками, воплощенными в мифологии» (Шкурина, 2011, с. 64).

Подводя определенный итог, можно сделать вывод, что инициация, может быть как возрастной, так и социальной. Под социальной инициацией понимается вступление посвящаемого (неофита) в сакральное тайное общество (в определенную социальную группу), или посвящение в религиозный сан. Данные социальные посвящения в тайные организации рассматривает Мирча Элиаде в работе: «Тайные общества. Обряды инициации и посвящения» (Элиаде, 1999). Для «входа» в тайное общество (социальную группу) посвящаемому необходимо проходить сложную процедуру (инициацию), которая напрямую зависит от самого тайного общества. Это тайное общество должно обладать определенными требованиями: архаичностью; процедурой посвящения; тайностью; сложными институтами; иерархичностью; агрессивной внешней средой (враги или условия бытия); сакральностью.

Но существуют ли сегодня такие архаичные социальные группы, в которых присутствует инициация? Какова грань между инициацией (посвящением) в специфический трудовой коллектив и простым испытательным сроком при устройстве на работу. Это первый из вопросов данной статьи, на который мы попытаемся ответить.

Второй вопрос заключается в наличии структурности в современной инициации. Идентифицировать инициацию в современном трудовом коллективе достаточно сложно, а структурировать и классифицировать еще сложнее.

\section{Теоретическое обоснование}

Выше упоминалось, что институт инициаций существует и сейчас, но в «специфических» (тайных) обществах. И. А Випулис проводит сравнение между архаичными инициациями и двумя современными закрытыми субкультурами наркосообществом и тюремной средой (Випулис, 2017а). Имеется множество сходств между инициациями в таких субкультурах с архаичными инициациями. И. А. Випулис упоминает главное: наркосообщество и тюремная среда явдяются закрытыми субкультурами (Випулис, 2017б). Следовательно «вход» в эти социальные группы строго лимитирован при помощи испытаний и инициаций, а все что происходит в таких группах строго сакрадьно и мифологизировано. Миф в таких коляективах выполняет особую роль. «Миф способствует организации коллектива, содействует сохранению его социальной и социально - психологической монолитности» (Штроо, Петрова, 2008, с. 8).

Специфичный трудовой коллектив, находящийся в социальной изоляции,закрыт, а значит сакрален. «Раздичают категории «профанное» и «сакрадьное» как две полярные и взаимодополнительные среды. Сакральное создается людьми, 
ПСИХОЛОГИЯ

оно питается, «заряжается» исходящей от них силой в процессе осуществления культовых практик» (Капишин, 2019, с. 2).

Инициация в коллектив АДК возможна, только когда молодой человек приходит из университета, или с абсолютно другой профессии, и устраивается на работу. Инициация невозможна если человек переходит из одного АДК на другой, при повышении в должности, или временном переводе. В таком случае, у человека имеются профессиональные навыки, опыт работы, авторитет.

В другой статье И. А. Випулис «Масонские посвящение как синтез древних традиций» рассматривается трансформация инициации, как социального инструмента, из древней архаичной возрастной инициации в современную инициацию тайных обществ (Випулис, 2017б). Современная инициация тайных обществ «включает»: возрастную, конфессиональную и профессиональную инициацию. Поэтому полноценная инициация возможна только тогда, когда новичок является достаточно молодым человеком, пришедшим в специфический трудовой коллектив.

Таким образом, инициация в специфическом трудовом колиективе заменяет человеку практически все жизненные этапы, особенно упоминавшийся кризис института инициаций и ритуалов (Дисина, 2017).

Для выявления структурности инициации в современном трудовом коллективе, обратимся к главному исследователю обрядов перехода Арнольду ванн Геннепа (Геннеп, 1999). Его фундаментальный труд «Обряды перехода» позволяет структурировать практически все обряды: рождение, инициация, свадьба, смерть (Геннеп, 1999.). «Ван Геннеп выделил в обрядах перехода три обязательные стадии: прелиминарную (отделение), лиминарную (промежуточную) и постлиминарную (включение), отметив, что все три стадии обряда перехода входят в каждый ритуальный цикл» (Тураев, 2017, с. 70).

Для выявления инициации в специальном трудовом коллективе, необходимо обозначить стадии перехода, которые не имеют ничего общего с формальной стажировкой пришедшего молодого специалиста. Инициация начинается с приходом последнего в коллектив АДК. Как правило, это самая младшая должность в коллективе АДК. Начинается первая стадия перехода - отделение. Длительность этого периода занимает день-два. У мододого специалиста спрашивают, какое высшее учебное заведение закончил, какие профессиональные навыки имеет. Неформально (подсознательно) ему показывают место в иерархии, формально прикрепляют за ним наставника, проводят шестидневную стажировку. В этой стадии новичка отделяют от прошиой социальной жизни. Его наставдяют на важность этой работы и на никчемность и мелочность всего, что было до этого. Можно сказать, происходит его «обнуление», его социальное - становится профанным, а впереди ждет обучение и принятие сакрального. 
Вторая стадия инициации является самой интересной и длительной во времени, она длится около месяца - двух, это промежуточная стадия. В архаичных обществах, на этой стадии, отражается все многообразие культуры. Практически все авторы, указанной дитературы данной статьи, классифицируют стадию как «состояние мертвеца». «Смерть в посвящении необходима как «начало» духовной жизни. Ее функция определяется тем, что она готовит рождение к более высокой форме жизни, к высшему предназначению» (Элиаде, 1999, с. 19). Достаточно вспомнить симводизм «смерти» и «рождения» в христианской культуре. Праздники Рождества, Пасха, это ежегодные обряды рождения и воскрешения.

Конечно, если сравнить промежуточную стадию обряда, связанную с «погружением» молодого специалиста в «состояние мертвеца», в современном специфическом трудовом коллективе, с промежуточной стадией обряда в архаичном обществе, которые описаны в «Золотой ветви» Д. Д. Фрэзера, то сходство имеется (Фрэзер, 1983). Эти сходства видны в коллективном бессознательном. В современности отсутствуют четко выраженные стадии обряда, они могут быть «размыты». Стажер-новичок в коллективе АДК, после стадии отделения, плавно переходит в «стадию мертвеца» (промежуточная стадия). Хотя, правильнее этот промежуточный переход обозначить как стадия «социальной смерти». Осуществляются действия, направленные на стажера (посвящаемого), которые «занижают» его социальный статус и «обнуляют» его профессиональный и жизненный опыт. Все это можно назвать «социальной смертью». Профессиональный опыт не волнует коллег, т. к. сама работа очень специфична, а жизненный опыт стажера (посвящаемого) очень мал. К началу промежуточной стадии можно отнести высказывания, направленные на стажера, вот примеры: «Нам все равно, где работал, эта работа особенная!», «Забудь все, чему учиди в институте», «Цвет диплома тут значения не имеет» и т. д. Статус такого стажера - новичка очень низок, к нему предъявдяют высокие требования. Безусловно, многое тут зависит и от дичностных качеств самого стажера - новичка, которому дают «новое имя». Новое имя символизирует как статус новичка, так и его личные качества. Обычно в коллективах АДК новичку могут дать следующие имена - прозвища: «Студент», «Мододой», «Стажер», «Ученик» и т. д. Изменение имени, при инициации, является обыденной практикой практически во всех архаических обществах. Данный процесс достаточно хорошо описан у Д. Д. Фрэзера (Фрэзер, 1983).

Зачастую у стажера - новичка имя может меняться на каждой стадии инициации. На стадии отделения - свое имя, на промежуточной стадии (стадия социального мертвеца) прозвище, и в финале, при стадии включения имя, которое заслужил. Все это аналогично происходит в архаичных тайных обществах. «После всех испытаний происходило «новое рождение» неофита, в знак чего новопосвященный получал новое имя. Этот элемент ритуала можно рассматривать как 
ПСИХОЛОГИЯ

имянаречение (один из закдючительных элементов древних инициаций). Причем каждый этап посвящения кандидата отмечался его временным имянаречением, отражающим постепенный качественный переход индивида» (Випулис, 2017б).

Во время промежуточной стадии происходит обучение стажера-новичка. Формально стажировка, как уже упоминалось, длится шесть дней, за которые учат основам профессии и элементарным технологическим операциям. Помимо формальной стажировки производится неформальные проверки. Стажера активно муштруют и проверяют на принятие норм, ценностей и правил коллектива. Проверяется главное качество новичка, это умение хранить тайны, жить под девизом: «Что случилось на вагоне - остается на вагоне».

В финале инициации, а именно стадии вкдючения (постлиминарная), стажерановичка в коллектив АДК обычно приурочивают к получению первой зарплаты, или, как говорят в большинстве производственных коллективах, «проставиться».

Современную инициацию в специадизированном трудовом колдективе ближе всего можно сравнить с современным неофициальным посвящением в тюремное сообщество, или с армейским сообществом. «Посвящение в уголовной субкультуре называют тюремной «пропиской». Архаичность обряда прописки подобна прямой трансмиссии явлений, характерных для примитивных культур. Этот вариант посвящения с архаической практикой тайного общества. В криминальной среде данной процедуре подлежат только потенциально возможные члены группы (в отдичие от армейских сообществ, где «прописку» проходят все новоприбывшие, поэтому их соотносят с возрастными архаическими посвящениями)» (Випулис, 2017а).

Название посвящения - «прописка», употребляемое в тюремном и армейских сообществах, подразумевает все стадии инициации, финал которых аналогичен последней стадии включения - «проставление». Финал (включение) заключается в единении, даже в празднике для новичка. Главным в финале вкдючения, это разделение общей трапезы с новым участником коляектива. Употребление «особенной еды», как правило, приготовленной (добытой) самим посвящаемым. Обычно говорят, что новый член коллектива «проставляется». Ничто так не объединяет, как разделение пищи. «Совместная трапеза, иди обычай есть и пить вместе бесспорно обряд вкдючения, собственно материального единения, того, что мы называем «таинством причастия» (Геннеп, 1999). Общественной трапезой обычно все не оканчивается. Коллектив, в благодарность за обильную еду, может подарить определенный подарок. Данный подарок показывает изменение социального статуса новичка. К подаркам, чаще всего относится элемент одежды, или аксессуар.

В качестве примера стадии включения, при инициации в специфическом трудовом коллективе, рассмотрим коллектив подводной лодки Российской Федерации. Кодлектив подводной иодки осуществляет свою деятельность 
в условиях социальной изоляции. Стадия отделения новичка начинается еще на берегу. В казарме, а далее в порту на самой лодке, новичка - стажера постоянно учат и муштруют - промежуточная стадия. Финал, для новичка начинается с выходом додки в море. Далее осуществляется плановое погружение лодки под воду. Для новичка этот выход и погружение лодки первое. В назначенное время командир лодки собирает всех новичков - подводников, которым предстоит финальное испытание. Испытание состоит в следующем. К потодку подвешивается молот - кувалда, которая сильно раскачивается. Новичок должен проявить сноровку, под аплодисменты и смех старших коллег поцеловать движущуюся, подобно маятнику, кувадду. Самое интересное, что тут присутствует элемент опасности, который всегда есть в каждой инициации. После новичку протягивают большую чашу с забортной водой, которую он должен выпить. Выпить забортную воду,- тоже является испытанием. Выпитая вода есть симвод единения, человек показывает единство с морем. В добавок, выпитая забортная вода - это напоминание о возможной гибели человека: «Каждый должен знать и помнить вкус забортной воды и больше его не пробовать». Теперь новичок может называться «подводником». Тут же следует трапеза - угощение и поздравление коллег, вручение отличительных значков, специальных документов. Данный пример показывает о существовании инициации, как института и в современных специфических колиективах.

\section{Обсуждение резудьтатов}

Потребность инициации, как института в современном обществе очень велика. Этот факт прослеживается на протяжении всей статьи. Но еще более в инициации, как институте, нуждаются специадизированные коллективы. При проведении курсов повышения квалификации в НОУ «Инфотранс» г. Самара, где обучаются специадисты АДК, работающие на вагонах-путеизмерителях КВ $А-П$, им был задан ряд вопросов, касающихся потребности в инициации и других обрядах и ритуалах. Большинство примеров обрядов и советов по их применению, у слушателей курсов, вызывали положительные эмоции. Но с пользой института обрядов большинство слушателей согласилось. В качестве примеров и инструментов, при инициации, был предложен целый комплекс технологий и правил.

Интересным фактом оказалось, что многие слушатели уже применяли различные обряды и ритуалы в коллективах АДК (вагонах-путеизмерителях). Эти обряды и ритуалы были не сознательно придуманы и применены, а стихийно организованы по случаю, можно сказать, колдективным бессознательным. На эти обрядовые и ритуальные правила каждый коллектив АДК придумал множество мифов и трактовок. При этом все мифы поддаются одинаковой классификации.

В целом слушатели курсов положительно отозвались о институте ритуалов и обрядов. По их словам, это позволяет работникам АДК 
ПСИХОЛОГИЯ

(вагонов-путеизмерителей) отвлекаться от тяжелой работы, социализироваться, способствует сплочению команды.

\section{Автор заявляет об отсутствии конфликтов интересов.}

\section{Питература}

Архангельская, А. С. (2010). Значение ритуала в управлении организацией. Социчология, 2, 145-151.

Випулис, И. В. (2019). Витальная и танатальная основа инициации. Вестник Санкт-Петербургского государственного института культуры, 4(41), 33-37.

Випулис, И. В. (2017). Архаические инициации и неофициальные посвящения в современности. Вестник Московского государственного университета культуры и искусств, 5(79), 129-137.

Випулис, И. В. (2017). Масонские посвящение как синтез древних традиций. Культура и образование, 4(27), 61-69.

Геннеп, А. В. (1999). Обрядь перехода. Систематическое изучение обрядов. М.: Издательская фирма «Восточная литература» РАН.

Дюркгейм, Э. (2018). Элементарные формы религиозной жизни: тотемическая система в Австралии. М.: Издательский дом «Дело» РАНХиГС.

Капишин, А. Е. (2019). Концепция сакрального во французской социологической школе. Общество: социология, психология, педагогика, 3, 1-6.

Кузьменков, В. А. (2018). Ритуалы как факторы возникновения ценностей. Социиально-политические науки, 1, 152-157.

Аисина, Е. А. (2017). Инициация как недостаточный ритуал современного социума. Фундаментальные аспекты психологического здоровья, 3-4, 23-26.

Петровская, О. А., Магадова, О. О. (2015). Ритуад как элемент корпоративной культуры организации. В А. А. Сукиасян (ред.) Современные концеецции развития науки. Сборник статей Международной научно-практической конференизии (С. 182-188). Уфа: Аэтерна.

Столяренко, Л. Д., Самыгин, С. И., Ганиева, Р. Х. (2007). Культурология: Учебное пособие. Изд. 3-е. М.: Издательский центр «МарТ».

Тураев, М. (2017). Обряды перехода в трактовке Арнодьда Ван Геннепа. Культура и образование, 4(27), 70-75.

Фрэзер, Д. Д. (1983). Золотая ветвв: Исследование магии и религии. 2-е изд. М.: Подитиздат.

Шкурина, Т. Г. (2011). Инициация как социальная практика. Вестник Самарского Государственного Университета, 85, 60-65.

Штроо, В. А., Петрова, Э. С. (2008). Групповой миф и целостность организации. Прикладная юридчческая психология, 2, 6-19. 
Элиаде, М. (1999). Тайные общества. Обряды иницииции и посвящения. СПб.: Университетская книга.

\section{References}

Arhangel'skaya, L. S. (2010). The meaning of the ritual in the management of the organization. Sotsiologiya, 2, 145-151. (in Russ.).

Durkheim, E. (2018). Elementary Forms of Religious Life: The Totemic System in Australia. Moscow: Publishing house "Delo" of RANEPA. (in Russ.).

Eliade, M. (1999). Secret societies. Rites of initiation and dedication. St. Petersburg: Universitetskaya kniga. (in Russ.).

Frezer, D. D. (1983). The Golden Bough: The Study of Magic and Religion. 2nd ed. Moscow: Politizdat. (in Russ.).

Gennep, A. v. (1999). Rites of passage. Systematic study of rituals. Moscow: Publishing company "Eastern Literature" of RAS. (in Russ.).

Kapishin, A. E. (2019). The concept of the sacred in the French sociological school. Society: sociology, psychology, pedagogy, 3, 1-6. (in Russ.).

Kuz'menkov, V. A. (2018). Rituals as factors in the emergence of values. Sociopolitical sciences, 1, 152-157. (in Russ.).

Lisina, E. A. (2017). Initiation as an insufficient ritual of modern society. Fundamental aspects of mental health, 3-4, 23-26. (in Russ.).

Petrovskaya, O. A., \& Magadova, O. O. (2015). Ritual as an element of the corporate culture of the organization. In A. A. Sukiasyan (ed.) Modern concepts of the development of science. Proceedings of the International Scientific and Practical Conference (pp. 182-188). Ufa: Aeterna. (in Russ.).

Shkurina, T. G. (2011). Initiation as a social practice. Vestnik of Samara State University, 85, 60-65. (in Russ.).

SHtroo, V. A., \& Petrova, E. S. (2008). Group myth and the integrity of the organization. Applied Legal Psychology, 2, 6-19. (in Russ.).

Stolyarenko, L. D., Samygin, S. I., \& Ganieva, R. H. (2007). Culturology: Textbook. 3rd ed. Moscow: Publishing Center "MarT". (in Russ.).

Turaev, M. (2017). Rites of passage as interpreted by Arnold Van Gennep. Culture and Education, 4(27), 70-75. (in Russ.).

Vipulis, I. V. (2019). The Vital and Thanatal Basis of Initiation. Vestnik of the St. Petersburg State Institute of Culture, 4(41), 33-37. (in Russ.).

Vipulis, I. V. (2017). Archaic initiations and informal initiations in modern times. Vestnik of Moscow State University of Culture and Arts, 5(79), 129-137. (in Russ.).

Vipulis, I. V. (2017). Masonic initiation as a synthesis of ancient traditions. Culture and Education, 4(27), 61-69. (in Russ.). 